\title{
Miscellany
}

\section{The Max Hamilton Memorial Prize}

The third international Max Hamilton Memorial Prize will be awarded at the 19th Congress of the CINP (Collegium Internationale NeuroPsychopharmacologicum) in Washington DC, USA. The award consists of $\$ 10,000$ US and an engraved plaque. The prize is given to a young scientist (age 40 or younger) in recognition of an outstanding contribution to psychopharmacology. Further information: Salomon Z. Langer, MD, Synthelabo Recherce, CINP Awards Committee, 31 Avenue Paul Vaillant Couturier, BP 110, 92225 Bagneux Cedex, France. Nominations should be received by Dr Langer by 15 January 1994.

\section{Breathing Space Campaign}

This campaign, organised by ASH (Action on Smoking and Health) promotes smoke-free air in public places, and has the support of more than $\mathbf{3 0}$ national organisations, including the Royal College of Psychiatrists. A campaign pack is available. Further information: Jeanette Longfield, ASH consultant, 109 Gloucester Place, London W1H 3PH.

\section{SANE}

SANE (Schizophrenia, A National Emergency) has received \$1 million (about $£ 750,000$ ) for research from King Fahd of Saudi Arabia. This is the second instalment of a pledge totalling $£ 1,750,000$ which King Fahd is contributing to SANE to establish a research centre in Oxford University aimed at discovering the causes, and eventually cures, for schizophrenia and other serious mental illness. King Fahd's donation was given on condition that it would be matched by others. The Xylas family, through Nicholas and Matti Egon will contribute the matching \$1 million. This leaves a further $£ 1$ million that SANE must raise to release the final instalment of King Fahd's gift.

\section{The Mental Health Foundation}

The Mental Health Foundation has published a new analysis which shows that $23 \%$ of children attending GP surgeries ( 2 million) have some form of severe psychological and emotional problem, but only $2 \%$ are identified by GPs $(173,000)$. Even in paediatric out-patient clinics, only one in three cases are identified. Further information: The Mental Health Foundation, 37 Mortimer Street, London WIN 7RJ.

\section{APA's Award for Research in Psychiatry}

The American Psychiatric Association has announced that William T. Carpenter, MD, Director of the Maryland Psychiatric Research Centre and Professor of Psychiatry at the University of Maryland School of Medicine, is co-winner of its 17th Annual Award for Research in Psychiatry.

\section{New journal}

The Therapist is a new journal published by the European Therapy Studies Institute. Further information: Deborah Jacobs, Information Controller, The Therapist, 196 Heene Road, Worthing, West Sussex BN1 1 4NT.

\section{Book Club}

The Book Club of the British Psycho-Analytical Society aims to promote psychoanalytic literature among professionals working in areas associated with mental health. Further information: Ann Glynn, BPS Book Club, The Institute of Psycho-Analysis, 63 New Cavendish Street, London W1M 7RD.

\section{CIDI-Auto}

The Composite International Diagnostic Interview is a fully structured diagnostic interview which was developed as a collaborative project between the World Health Organisation and the US Alcohol, Drug Abuse, and Mental Health Administration. The CIDI Training Centre, Sydney, has produced a computerised CIDI, known as CIDI-Auto, for the World Health Organisation. It will run on any IBM compatible machine with a hard disk or on a machine without a hard disk by using a pair of $1.44 \mathrm{Mb} 3.5$ inch floppy disks. Further information: WHO CIDI Training and Reference Centre, 299 Forbes Street, Sydney, NSW 2010, Australia (fax 612332 4316).

\section{Leaflet for ME sufferers}

Coping with $M E$ is a free leaflet available from Action for ME, P.O. Box 1302, Wells, BA5 2WE. 